\title{
E-BOOK
}

\section{AMPLAMENTE MULTIDISCIPLINAR ESTUDOS E PRÁTICAS CONTEMPORÂNEAS}

\author{
ORGANIZADORES
}

Luciano Luan Gomes Paiva

Dayana Lúcia Rodrigues de Freitas

Caroline Rodrigues de Freitas Fernandes

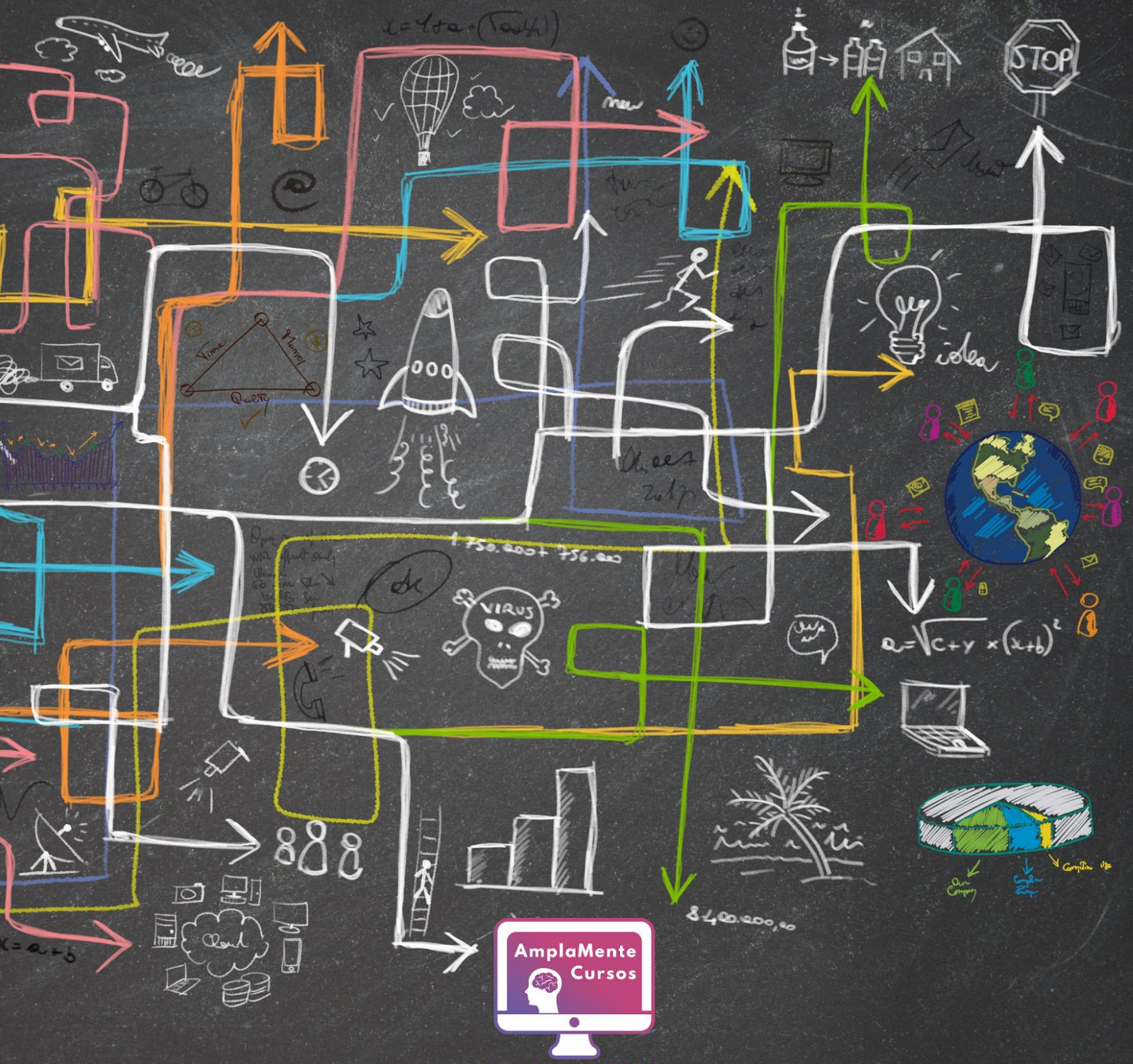




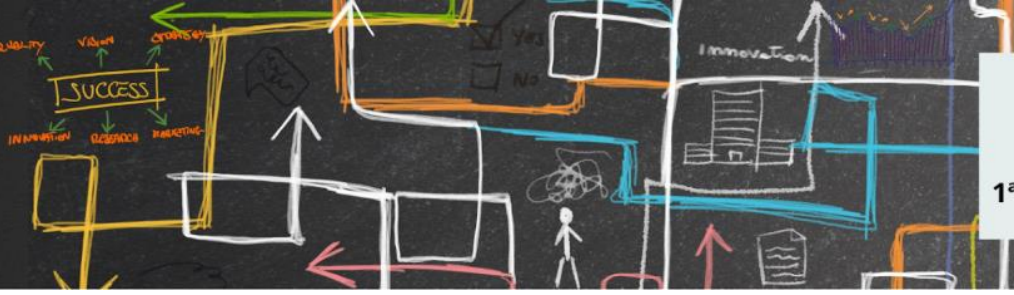

AMPLAMENTE MULTIDISCIPLINAR: ESTUDOS E PRÁTICAS CONTEMPORÂNEAS $1^{\text {a }}$ ED VOL. 1 ISBN: 978-65-89928-05-8 DOI: 10.47538/AC-2021.07

\section{E-BOOK}

\section{ATIPIATIDNHE}

\section{MULTIDISCIPLINAR:}

\section{ESTUDOS E PRÁTICAS CONTHMPORÂNHAS}

$1^{\text {a }}$ EDIÇÃO. VOLUME 01.

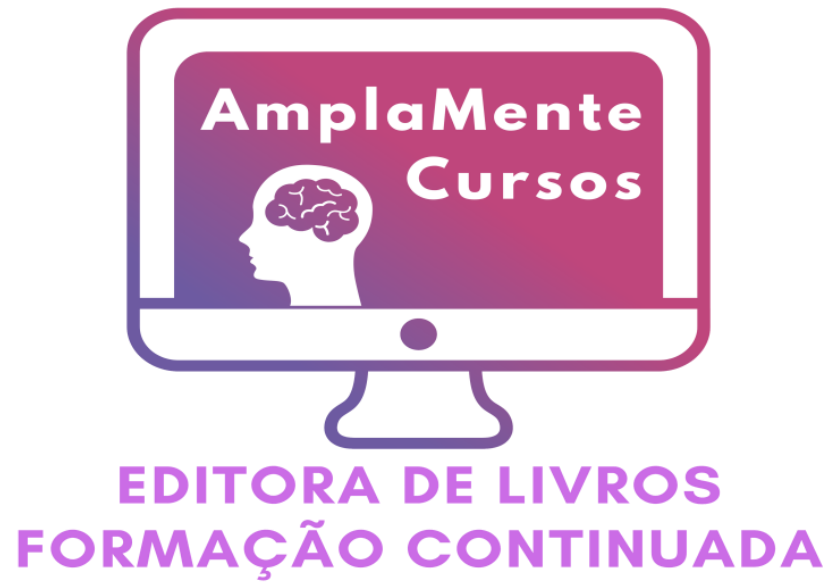

ORGANIZADORES

Luciano Luan Gomes Paiva

Dayana Lúcia Rodrigues de Freitas

Caroline Rodrigues de Freitas Fernandes

DOI: 10.47538/AC-2021.07
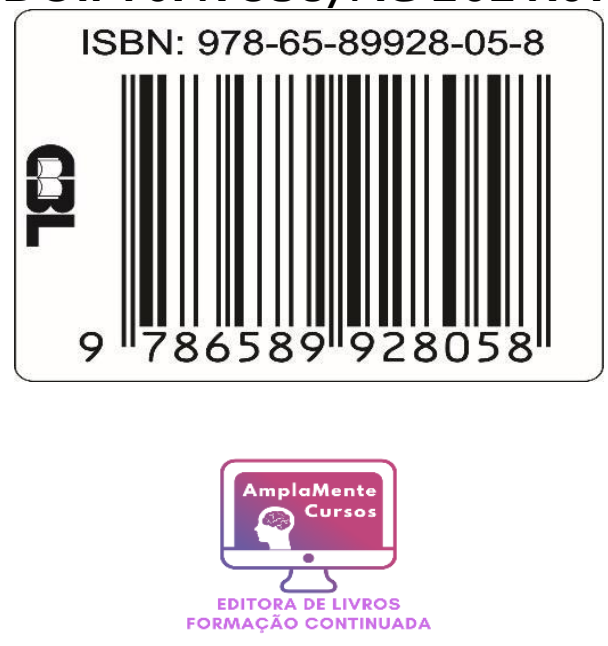

Ano 2021 


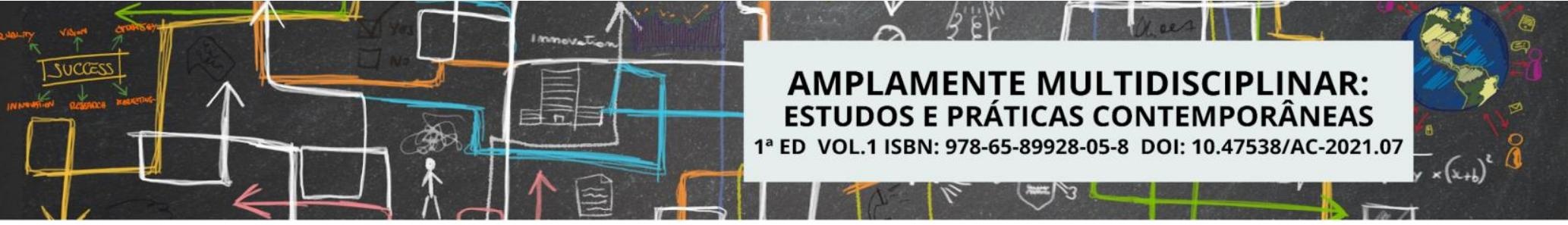

Editora Chefe:

Dayana Lúcia Rodrigues de Freitas

Assistentes Editoriais:

Caroline Rodrigues de F. Fernandes

Maria Pollyana Sales Vicente

Margarete Freitas Baptista

Bibliotecária:

Maria Alice Ferreira

Aline Graziele Benitez

Projeto Gráfico e Diagramação:

Luciano Luan Gomes Paiva

Caroline Rodrigues de F. Fernandes

Imagem da Capa: 2021 by Amplamente Cursos e Formação Continuada

Shutterstock Copyright (C) Amplamente Cursos e Formação Continuada

Edição de Arte: Copyright do Texto (C) 2021 Os autores

Luciano Luan Gomes Paiva Copyright da Edição (C) 2021 Amplamente Cursos e

Formação Continuada

Revisão: Direitos para esta edição cedidos pelos autores à

Os autores Amplamente Cursos e Formação Continuada.

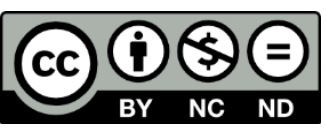

Todo o conteúdo deste livro está licenciado sob uma Licença de atribuição Creative Commons. Atribuição-NãoComercialSemDerivações 4.0 Internacional (CC-BY-NC-ND).

Este e-book contém textos escritos por autores de diversos lugares do Brasil e, possivelmente, de fora do país. Todo o conteúdo escrito nos capítulos, assim como correção e confiabilidade são de inteira responsabilidade dos autores, inclusive podem não representar a posição oficial da Editora Amplamente Cursos.

A Editora Amplamente Cursos é comprometida em garantir a integridade editorial em todas as etapas do processo de publicação. Todos os artigos foram previamente submetidos à avaliação cega pelos pares, membros do Conselho Editorial desta Editora, tendo sido aprovados para a publicação.

É permitido o download desta obra e o compartilhamento desde que sejam atribuídos créditos aos autores, mas sem a possibilidade de alterá-la de nenhuma forma ou utilizá-la para fins comerciais.

Situações de má conduta ética e acadêmica ou quaisquer outros problemas que possam vir a surgir serão encaminhados ao Conselho Editorial para avaliação sob o rigor científico e ético.

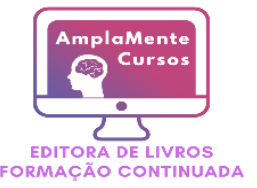




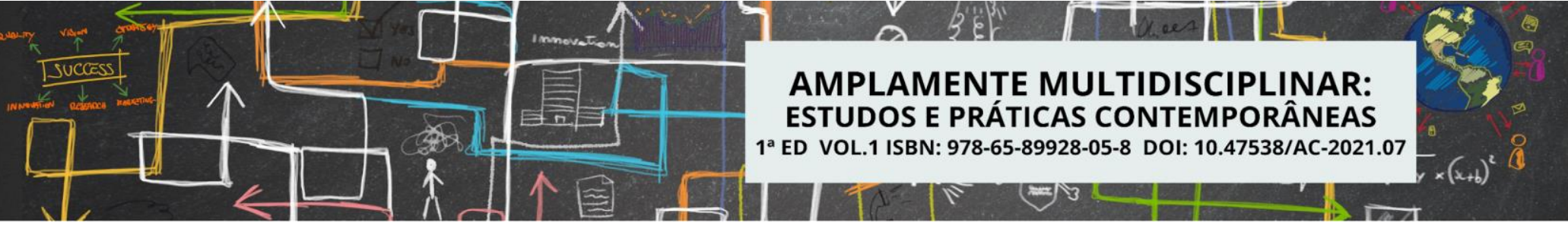

\section{CONSELHO EDITORIAL}

Dr. Damião Carlos Freires de Azevedo - Universidade Federal de Campina Grande

Dra. Danyelle Andrade Mota - Universidade Federal de Sergipe

Dra. Débora Cristina Modesto Barbosa - Universidade de Ribeirão Preto

Dra. Elane da Silva Barbosa - Universidade Estadual do Ceará

Dra. Eliana Campêlo Lago - Universidade Estadual do Maranhão

Dr. Everaldo Nery de Andrade - Universidade Estadual do Sudoeste da Bahia

Dra. Fernanda Miguel de Andrade - Universidade Federal de Pernambuco

Dr. Izael Oliveira Silva - Universidade Federal de Alagoas

Dr. Jakson dos Santos Ribeiro - Universidade Estadual do Maranhão

Dra. Josefa Gomes Neta - Faculdade Sucesso

Dr. Maykon dos Santos Marinho - Faculdade Maurício de Nassau

Dr. Rafael Leal da Silva - Secretaria de Educação e da Ciência e Tecnologia da Paraíba

Dra. Ralydiana Joyce Formiga Moura - Universidade Federal da Paraíba

Dra. Roberta Lopes Augustin - Faculdade Murialdo

Dra. Smalyanna Sgren da Costa Andrade - Universidade Federal da Paraíba

Dra. Viviane Cristhyne Bini Conte - Universidade Tecnológica Federal do Paraná

Dr. Wanderley Azevedo de Brito - Instituto Federal de Educação, Ciência e Tecnologia de Goiás

\section{CONSELHO TÉCNICO CIENTÍFICO}

Ma. Ana Claudia Silva Lima - Centro Universitário Presidente Tancredo de Almeida Neves

Ma. Andreia Rodrigues de Andrade - Universidade Federal do Piauí

Esp. Bruna Coutinho Silva - Pontifícia Universidade Católica de Minas Gerais

Ma. Camila de Freitas Moraes - Universidade Católica de Pelotas

Me. Carlos Eduardo Krüger - Universidade Regional Integrada do Alto Uruguai e das Missões

Esp. Caroline Rodrigues de Freitas Fernandes - Escola Ressurreição Ltda.

Me. Clécio Danilo Dias da Silva - Universidade Federal do Rio Grande do Norte

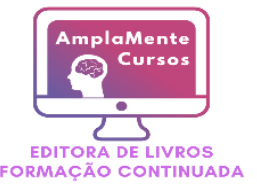




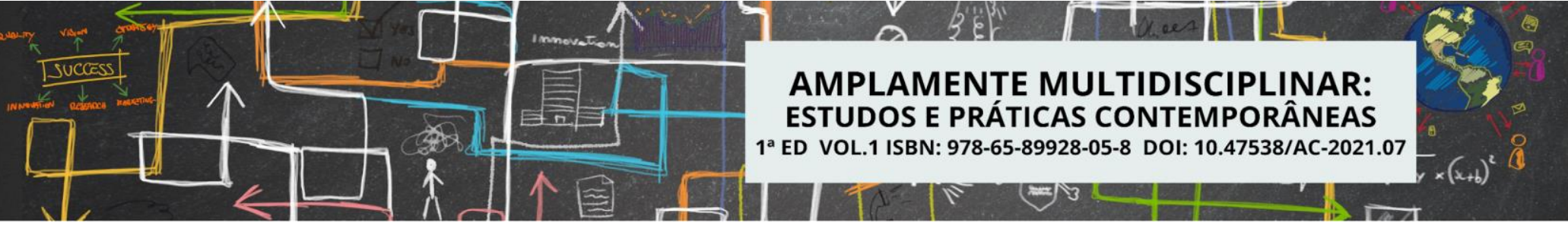

Me. Fabiano Eloy Atílio Batista - Universidade Federal de Viçosa

Me. Francisco Odécio Sales - Instituto Federal de Ciência e Tecnologia do Ceará

Me. Fydel Souza Santiago - Secretaria de Educação do Estado do Espírito Santo

Me. Giovane Silva Balbino - Universidade Estadual de Campinas

Ma. Heidy Cristina Boaventura Siqueira - Universidade Estadual de Montes Claros

Me. Jaiurte Gomes Martins da Silva - Universidade Federal Rural de Pernambuco

Me. João Antônio de Sousa Lira - Instituto Federal de Educação, Ciência e Tecnologia do Maranhão

Me. João Paulo Falavinha Marcon - Faculdade Campo Real

Me. José Henrique de Lacerda Furtado - Instituto Federal de Educação, Ciência e Tecnologia do Rio de Janeiro

Me. José Flôr de Medeiros Júnior - Universidade de Uberaba

Ma. Josicleide de Oliveira Freire - Universidade Federal de Alagoas

Me. Lucas Peres Guimarães - Instituto Federal de Educação, Ciência e Tecnologia do Rio de Janeiro

Ma. Luma Mirely de Souza Brandão - Universidade Tiradentes

Me. Marcel Alcleante Alexandre de Sousa - Universidade Federal da Paraíba

Me. Márcio Bonini Notari - Universidade Federal de Pelotas

Ma. Maria Antônia Ramos Costa - Instituto Federal de Educação Ciência e Tecnologia de Rondônia

Ma. Maria Inês Branquinho da Costa Neves - Universidade Católica Portuguesa

Me. Milson dos Santos Barbosa - Universidade Tiradentes

Ma. Náyra de Oliveira Frederico Pinto - Universidade Federal do Ceará

Me. Paulo Roberto Meloni Monteiro Bressan - Faculdade de Educação e Meio Ambiente

Ma. Rosiane Correa Guimarães - Universidade Federal de Jataí

Ma. Sirlei de Melo Milani - Universidade do Estado de Mato Grosso

Ma. Viviane Cordeiro de Queiroz - Universidade Federal da Paraíba

Me. Weberson Ferreira Dias - Instituto Federal de Educação, Ciência e Tecnologia do Tocantins

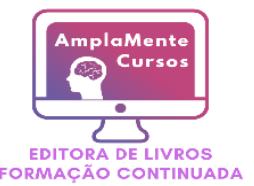




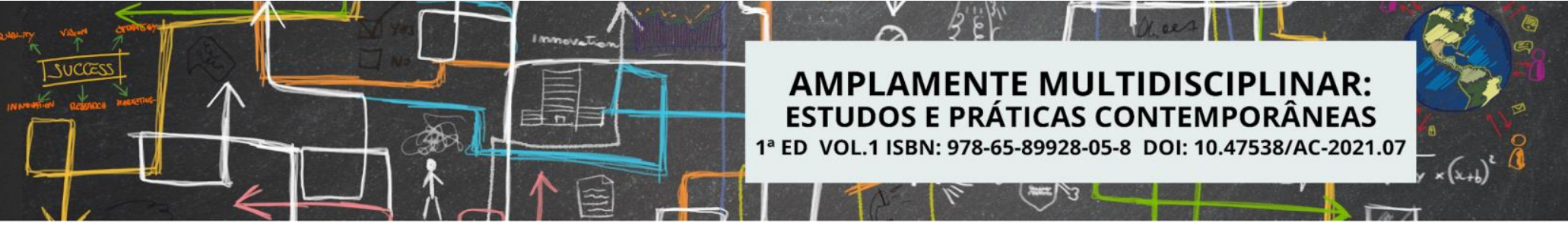

\section{DECLARAÇÃO DOS AUTORES}

Todos os autores desta obra declaram que trabalharam ativamente na produção dos seus trabalhos, desde o planejamento, organização, criação de plano de pesquisa, revisão de literatura, caracterização metodológica, até mesmo na construção dos dados, interpretações, análises, reflexões e conclusões. Assim como, atestam que seus artigos não possuem plágio acadêmico, nem tampouco dados e resultados fraudulentos. Os autores também declaram que não possuem interesse comercial com a publicação do artigo, objetivando apenas a divulgação científica por meio de coletâneas em temáticas específicas. 


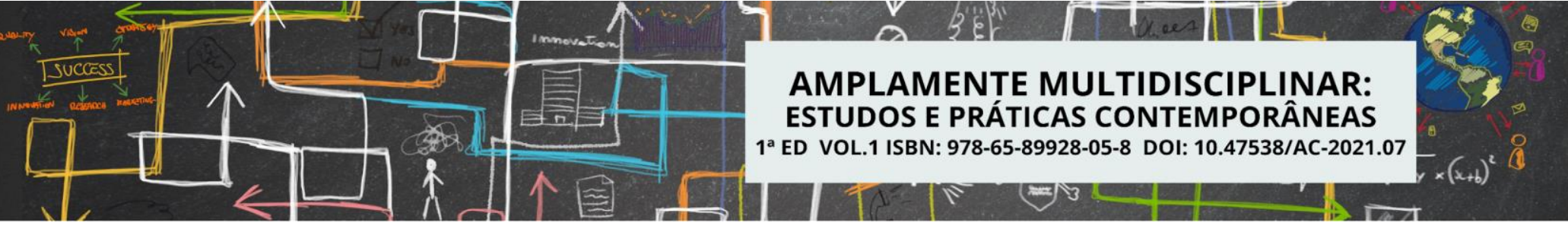

\section{APRESENTAÇÃO}

O E-book Amplamente Multidisciplinar: estudos e práticas contemporâneas tratase de uma coletânea de textos científicos, oriundos de estudos teóricos e práticos em diversas áreas de conhecimento. Com estudos analíticos de casos isolados, o livro busca a difusão do conhecimento científico de maneira multidisciplinar, direcionando-se, especificamente, a profissionais pesquisadores de todo Brasil.

As pesquisas científicas em diversas áreas de conhecimento vêm, cada vez mais, necessitando de novos paradigmas para sua continuidade no avanço e difusão de conhecimento. Um possível caminho é a articulação de trabalhos de áreas distintas, cruzando autores, estudos e práticas em uma perspectiva multidisciplinar.

Desta forma, estruturamos este livro com estudantes, profissionais e pesquisadores, objetivando a colaboração de suas pesquisas, podendo pertencer a diversas áreas de conhecimento como: Ciências Humanas; Ciências da Saúde; Ciências Sociais Aplicadas; Ciências Biológicas; Linguística, Letras e Artes; Engenharias; Ciências Exatas e da Terra; e Ciências Agrárias.

Assim sendo, em nome da Editora Amplamente Cursos, convido a todas as pessoas para a leitura do E-book Amplamente Multidisciplinar: estudos e práticas contemporâneas, para conhecer propostas, concepções, problemáticas, perspectivas, melhorias, apontamentos, análises entre outras questões importantes para a difusão do conhecimento científico.

Boa Leitura!

Luciano Luan Gomes Paiva

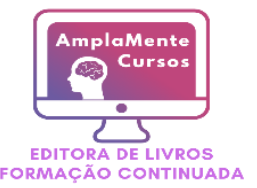




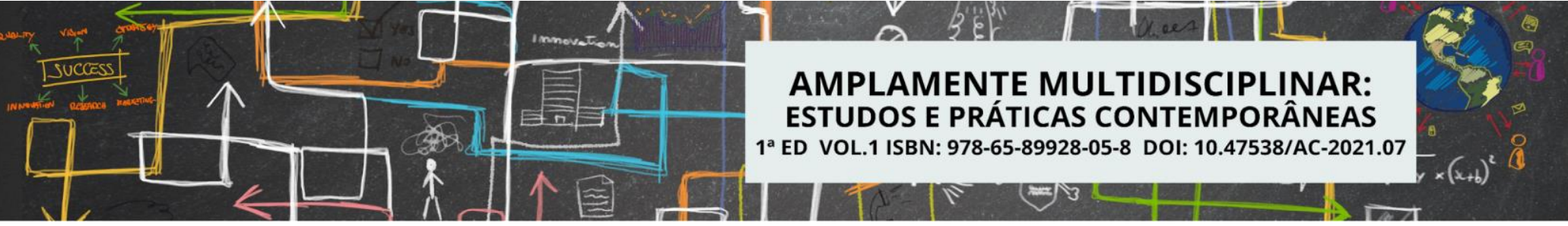

na eleição.

Em outras palavras, em um sistema de votação proporcional, partidos ou coalizões, e muitas vezes até mesmo um único candidato, como no caso do ex-membro do Parlamento Europeu Enéas Carneiro, ganha uma cadeira no Parlamento cada vez que alcança um certo número de votos. Este número específico de votos é chamado de quociente eleitoral no Brasil, que explicaremos com mais detalhes.

O senador Marco Maciel (2001, p. 10) toma uma posição muito forte no sistema eleitoral que melhor se adequa ao Brasil. Maciel argumenta que "não há razões boas ou óbvias para justificar uma mudança de um sistema proporcional para um sistema majoritário", a fim de introduzir um "puro sistema de votação distrital".

Maciel (2001, p. 10) argumenta que "a adoção de um sistema chamado erroneamente de "sistema de distritos mistos", que na realidade é o modelo alemão, não viola a disposição constitucional na medida em que a conversão de votos em assentos é feita na proporção do número de votos de cada partido". Ele continua dizendo que "a maneira como os assentos vagos são preenchidos, sim, é tal que atende ao critério de prover assentos para os eleitos em cada circunscrição eleitoral e os assentos restantes são preenchidos de acordo com o lugar em cada lista. Isto significa que o número real de assentos no Parlamento, como foi o caso nas eleições de 1995 na Alemanha, pode ser fixo, mas com algumas flutuações".

Por outro lado, o senador Marco Maciel também apoia a mudança, argumentando que, se o sistema eleitoral proporcional for mantido, deve ser com listas fechadas para fortalecer os partidos, ligando o eleitor ao partido e não ao candidato, como é o caso agora.

\section{O SISTEMA DISTRITAL}

Um sistema de votação distrital puro é a introdução de um sistema de maioria simples nas eleições municipais, estaduais ou federais, cuja característica especial é que os candidatos que recebem o maior número de votos são eleitos em seus círculos eleitorais (NICOLAU, 2012). 


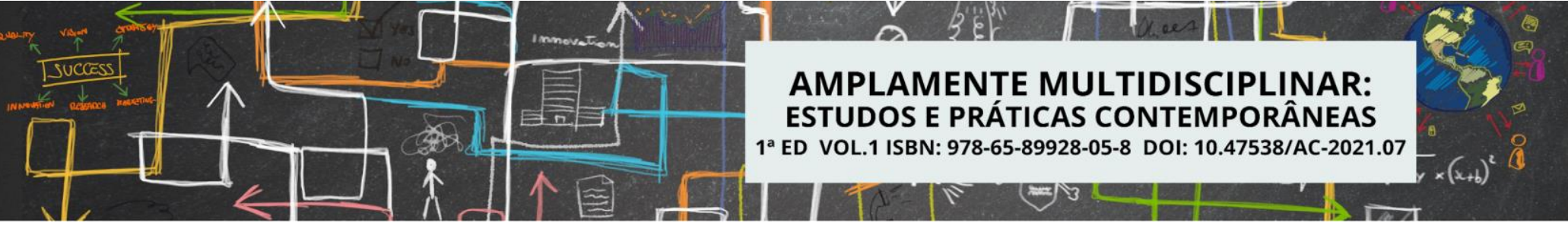

\section{REFERÊNCIAS}

BARDIN, Laurence. Análise de Conteúdo. Presses Univcrsitaires de France. 1977

CERQUEIRA, Thales Tácito Pontes Luz de Pádua. Direito Eleitoral Brasileiro. 2011

DALLARI, Dalmo de Abreu. Elementos de Teoria Geral do Estado. 30.ed. São Paulo: Saraiva, 2013

GIL, Antônio Carlos. Métodos e Técnicas de Pesquisa. 6a edição. Editora Atlas. São Paulo. 2006

GOMES, José Jairo. Direito Eleitoral. 16 Ed. São Paulo: Atlas Jurídico, 2011

MARCIEL, Marco. As necessárias reformas políticas. Cidadania e Justiça. São Paulo, ano X, no 10, págs. 6 a 12, setembro de 2001

MARTINS, Gilberto Andrade; THEÓPHILO, Carlos Renato. Metodologia da investigação científica para ciências sociais aplicadas. 9 ed. São Paulo: Atlas, 2016.

MENDES, Gilmar Ferreira; BRANCO, Paulo Gustavo. Curso de direito constitucional. 7a. ed. rev. e atual. - São Paulo: Saraiva, 2012

NICOLAU, Jairo. Eleições no Brasil: do império aos dias atuais. Rio de Janeiro: Zahar, 2012

PRODANOV, Clber Cristiano; FREITAS, Ernani Cesar de. Metodologia do Trabalho Científico: Métodos e Tecnicas da Pesquisa e do Trabalho Acadêmico. $2^{\text {a }}$ Edição. Novo Hamburgo: Feevale, 2013.

OLIVEIRA, Noelle; RODRIGUES, Léo. Como funciona uma coligação partidária. Eleições 2016. Disponível em: <https://www.eleicoes2016.com.br/como-funciona-umacoligacao-partidaria/>. Acesso em julho de 2021.

RAMAYANA, Marcos.Direito Eleitoral. 12. Ed. Rio de Janeiro: Impetus, 2011 


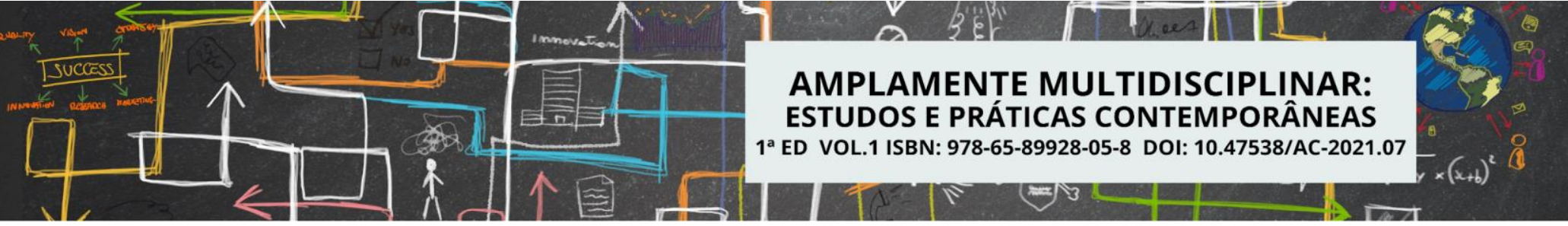

população de aproximadamente 55 mil habitantes e é banhado pelo rio Acará, cuja foz é na baia de Guajará de frente para cidade de Belém do Pará (fig. 1).

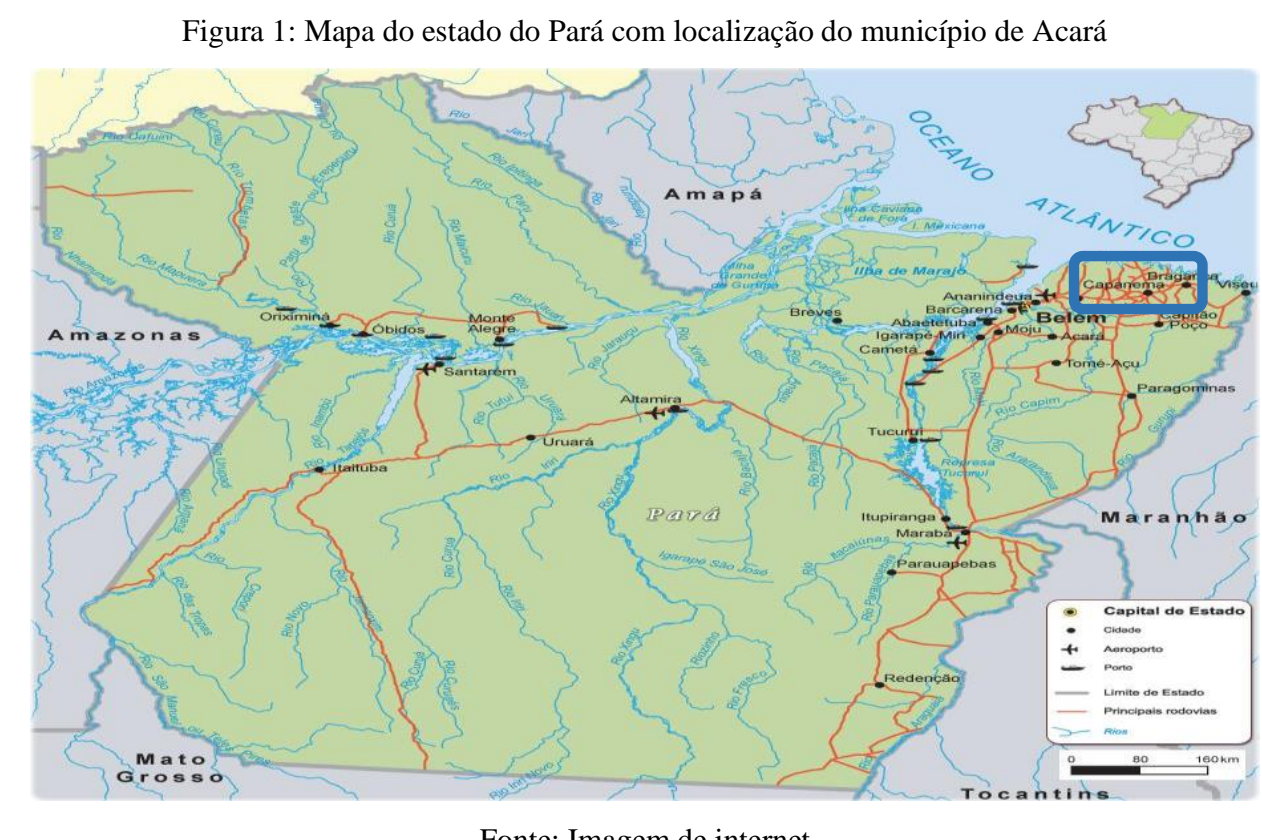

Fonte: Imagem de internet

\section{COMUNIDADE BOA ESPERANÇA/ASSENTAMENTO SÃO LOURENÇO}

A localidade Boa Esperança (Fig. 2), surgiu em meados de 1969-1980, tendo como principais fundadores e primeiros moradores, sete pessoas que desenvolviam atividades de cunho religioso como novenas e ladainhas nas casas vizinhas, essas famílias se desenvolveram e foram povoando a localidade (SANTOS, 2019, p. 13).

A economia era desenvolvida por meio da troca de mercadorias, os produtos comercializados eram trocados por objetos, ferramentas, roupas e outros. Utilizando-se do rio como via e as canoas como transporte, pelo fato do acesso a cidade de Acará ser muito difícil, a comercialização ficava somente entre os moradores da localidade. Nos dias atuais a localidade conta com ramal de acesso ao centro do município onde podem receber atendimentos para as necessidades básicas da sociedade. Conta também com comércios, transporte escolar e uma biodiversidade que tem elevado a economia das famílias que trabalham na produção agrícola de mandioca, açaí, macaxeira, bacaba, abacaxi, urucu, entre outros (Fig.2). 


\section{O PATRIMÔNiO AMBIENTAL: A PERCEPÇÃo dOS GESTORES, DOS PROFESSORES E DO CONDUTOR DA EMBARCAÇÃO}

Trataremos das percepções que os profissionais da educação da escola, lócus deste estudo, possuem acerca do que é patrimônio ambiental para os alunos, com os quais eles convivem cotidianamente e se eles conseguem perceber o rio Acará como patrimônio.

Desta forma, o estudo de práticas de Educação Ambiental, instiga para a educação e os seus profissionais a construção de elementos teóricos sobre as práticas e o desenvolvimento de novas metodologias, bem como estimula a consciência crítica do sujeito acerca das relações com o seu ambiente, e produz novas condutas capazes de levar as pessoas a se envolverem com as questões ambientais e valorização de seus patrimônios naturais (SILVA; SILVA; 2017, p. 25).

No que se refere à percepção do rio, observa-se que os entrevistados se apropriam do rio como parte de suas vidas, pois ele está inserido em todas as esferas do seu dia a dia, quer seja para consumo ou para lazer. As gestoras, em comum, destacam o bem que o rio lhes proporciona, inclusive para a saúde emocional, "estar em uma comunidade ribeirinha mudou minha vida, melhorou minha saúde e me traz tranquilidade. Poder apreciar o rio da minha janela todas as manhãs fez com que eu me apaixonasse por ele" (ENTREVISTA GESTORA ESCOLAR, 2019), e "é gostoso ir para a ponte, observar o rio a tarde e sentir o vento" (ENTREVISTA VICE GESTORA, 2019).

A avaliação dos entrevistados em relação ao posicionamento dos alunos quanto a valorização do rio como patrimônio ambiental revela que não há sentimento de valorização ou de pertença ao rio. Esta afirmação está pautada no que estes profissionais observam no dia a dia escolar e destacam em seus depoimentos, nos quais afirmam como a gestora da escola, que "os próprios alunos jogam lixo no rio e não há este sentimento de que o rio que passa na frente da minha casa é minha vida. Infelizmente o rio não tem o respeito que merece" (ENTREVISTA GESTORA ESCOLAR, 2019).

Confirmada pela vice gestora quando afirma que "me sinto triste, pois antigamente não se via tudo isso de lixo no rio e hoje há certa poluição, pouco tomo banho no rio, pois já senti coceiras na pele" (ENTREVISTA VICE GESTORA, 2019) e reafirmada pelo condutor "A cada dia percebo mais poluição nas proximidades do rio e 


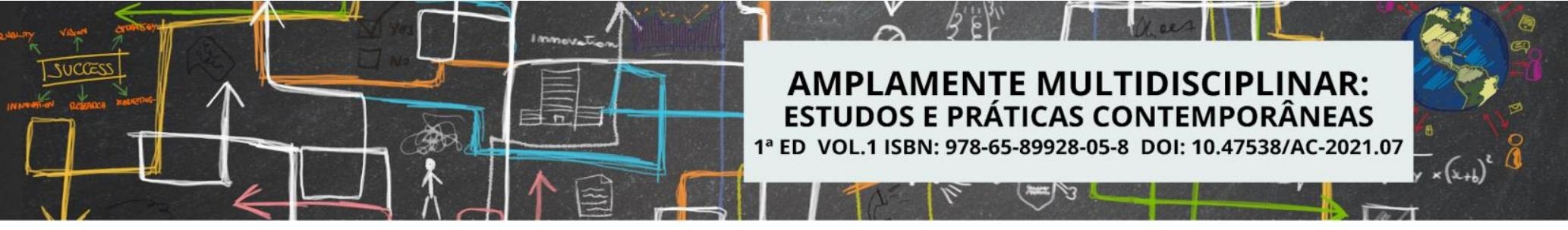

ciência, tecnologia e inovação.

$\S 2^{\circ}$ A pesquisa tecnológica voltar-se-á preponderantemente para a solução dos problemas brasileiros e para o desenvolvimento do sistema produtivo nacional e regional.

$\S 3^{\circ} \mathrm{O}$ Estado apoiará a formação de recursos humanos nas áreas de ciência, pesquisa, tecnologia e inovação, inclusive por meio do apoio às atividades de extensão tecnológica, e concederá aos que delas se ocupem meios e condições especiais de trabalho.

$\S 4^{\circ} \mathrm{A}$ lei apoiará e estimulará as empresas que invistam em pesquisa, criação de tecnologia adequada ao País, formação e aperfeiçoamento de seus recursos humanos e que pratiquem sistemas de remuneração que assegurem ao empregado, desvinculada do salário, participação nos ganhos econômicos resultantes da produtividade de seu trabalho.

$\S 5^{\circ}$ É facultado aos Estados e ao Distrito Federal vincular parcela de sua receita orçamentária a entidades públicas de fomento ao ensino e à pesquisa científica e tecnológica.

$\S 6^{\circ} \mathrm{O}$ Estado, na execução das atividades previstas no caput, estimulará a articulação entre entes, tanto públicos quanto privados, nas diversas esferas de governo.

$\S 7^{\circ} \mathrm{O}$ Estado promoverá e incentivará a atuação no exterior das instituições públicas de ciência, tecnologia e inovação, com vistas à execução das atividades previstas no caput.

Art. 219. O mercado interno integra o patrimônio nacional e será incentivado de modo a viabilizar o desenvolvimento cultural e sócioeconômico, o bem-estar da população e a autonomia tecnológica do País, nos termos de lei federal.

Parágrafo único. O Estado estimulará a formação e o fortalecimento da inovação nas empresas, bem como nos demais entes, públicos ou privados, a constituição e a manutenção de parques e polos tecnológicos e de demais ambientes promotores da inovação, a atuação dos inventores independentes e a criação, absorção, difusão e transferência de tecnologia.

Art. 219-A. A União, os Estados, o Distrito Federal e os Municípios poderão firmar instrumentos de cooperação com órgãos e entidades públicos e com entidades privadas, inclusive para o compartilhamento de recursos humanos especializados e capacidade instalada, para a execução de projetos de pesquisa, de desenvolvimento científico e tecnológico e de inovação, mediante contrapartida financeira ou não financeira assumida pelo ente beneficiário, na forma da lei.

Art. 219-B. O Sistema Nacional de Ciência, Tecnologia e Inovação (SNCTI) será organizado em regime de colaboração entre entes, tanto públicos quanto privados, com vistas a promover o desenvolvimento científico e tecnológico e a inovação.

$\S 1^{\circ}$ Lei federal disporá sobre as normas gerais do SNCTI.

$\S 2^{\circ}$ Os Estados, o Distrito Federal e os Municípios legislarão concorrentemente sobre suas peculiaridades. (BRASIL, 1988) 


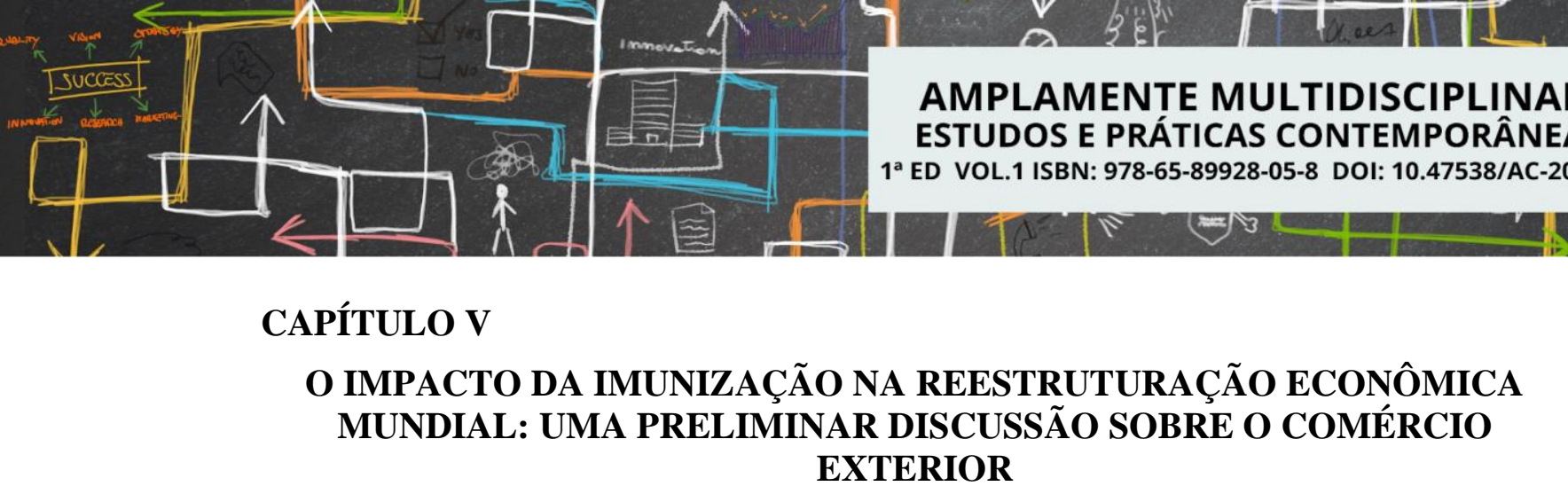

Wallace Moacir Paiva Lima'; Fernando Bastos Mendes ${ }^{10}$. DOI-CAPÍTULO: 10.47538/AC-2021.07-05

\title{
RESUMO:
}

O mundo está atualmente passando pela pandemia coronavírus, as consequências das quais afetam não só a saúde humana, mas que tem permeado as esferas sociais e econômicas de todas as nações. No cenário econômico global, o comércio internacional é um dos fatores mais impactantes devido ao COVID-19, sob os arranjos de contenção feitos pelas nações em resposta à atual crise de saúde. Os países implementaram medidas que promovam o isolamento social e outras ações contenciosas que causaram uma diminuição significativa no movimento das pessoas e, portanto, na atividade econômica e, em particular, comercial. Em relação ao exposto, as barreiras impostas nos principais mercados internacionais reduzem o consumo, a demanda e o investimento, portanto, estima-se um grande impacto nas atividades que envolvem a troca de produtos, bens e serviços que cruzam as fronteiras dos países e, cujo principal elemento dinâmico é o comércio internacional. Como se sabe, o fenômeno da globalização possibilitou que as relações internacionais no campo comercial fossem um elemento vital para a sobrevivência dos países e, nesse contexto, deve-se ter em mente que o impacto do coronavírus no comércio internacional tem sua origem na China, a origem das cadeias pandêmicas e globais de valor, que é o principal destino das exportações das commodities de várias economias latino-americanas.

PALAVRAS-CHAVE: COVID-19. Transporte Internacional. Comércio Exterior.

\section{THE IMPACT OF IMMUNIZATION ON WORLD ECONOMIC RESTRUCTURING: A PRELIMINARY DISCUSSION ON FOREIGN TRADE}

\begin{abstract}
:
The world is currently experiencing the coronavirus pandemic, the consequences of which not only affect human health, but which have permeated the social and economic spheres of all nations. In the global economic scenario, international trade is one of the most impacting factors due to COVID-19, under the containment arrangements made by nations in response to the current health crisis. The countries implemented measures that promote social isolation and other contentious actions that caused a significant decrease in the movement of people and, therefore, in economic and, in particular, commercial activity. In relation to the above, the barriers imposed in the main international markets reduce consumption, demand and investment, therefore, a great impact is estimated on

\footnotetext{
${ }^{9}$ Wallace Moacir Paiva Lima é bacharel em Ciência Política e Relações Internacionais pelo Centro Universitário Internacional - UNINTER PR. E-mail: wmpaivalima@gmail.com

${ }^{10}$ E-mail: bmsm.anestesia@gmail.com
} 


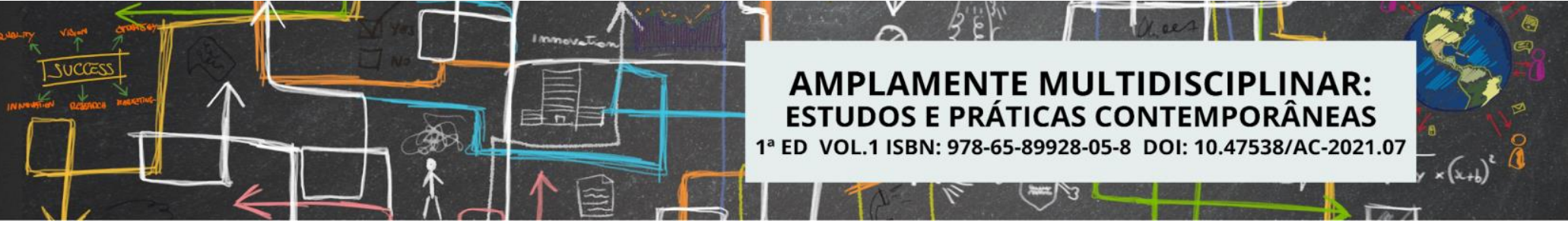

As consequências a longo prazo da pandemia do COVID-19 ainda são imprevisíveis, mas parece inevitável que oportunidades mais amplas surjam. Por conseguinte, espera-se que os empresários demonstrem flexibilidade e adaptem seus modelos de negócios em resposta a uma crise (KUCKERTZ, 2020).

Analisando especificamente a questão de logística, em diversos estudos (RODRIGUES et al., 2018; JAYARAM; TAN, 2010; MORANA; GONZALEZ-FELIU, 2017) nota-se à importância de manter uma estrutura de custos competitiva, oferecer serviços inovadores e lidar com fatores que impactam a eficiência e integridade dos produtos é imprescindível investir em inovações para o segmento logístico.

Operadores logísticos têm aumentado sua participação na indústria de serviços logísticos devido à crescente terceirização destes serviços nas últimas duas décadas. Empresas responsáveis por esse tipo de terceirização oferecem normalmente pacotes de serviços que incluem não apenas o transporte em si, mas também informações associadas ao serviço de transporte. Uma das razões do crescimento das atividades terceirizadas é decorrente do incremento da competitividade observada no mercado. Isto forçou empresas a direcionar seus esforços para suas atividades principais, que são críticas para sua sobrevivência. Desta forma, as atividades logísticas acabam tendo maior grau de terceirização, por não ser parte do negócio central da empresa. Com isso, cria-se a necessidade de contratar empresas operadoras logísticas, que muitas vezes ajudam na expansão do alcance dos produtos, junto à melhoria na qualidade dos serviços (FRIES; ZAMONER; CHRISTMANN, 2016).

Conforme se verifica os operadores logísticos desenvolvem uma ampla gama de serviços que incluem: transporte, armazenagem, gerenciamento de estoques, atividades relacionadas à informação, montagem e instalação de produtos, gerenciamento da cadeia de abastecimento entre outros (BRANSKI, 2010).

Percebe-se grande interesse por parte das empresas e do meio acadêmico nas atividades de seleção, negociação e contratação de operadores logísticos. Este interesse é motivado, em grande parte, pela complexidade do processo decisório aliada à importância destas decisões no ambiente de negócios. A terceirização de serviços logísticos pode ser realizada por meio de um Operador Logístico (OPL), qual seja: um fornecedor de serviços especializados em gerenciar e executar as atividades logísticas em diferentes processos 


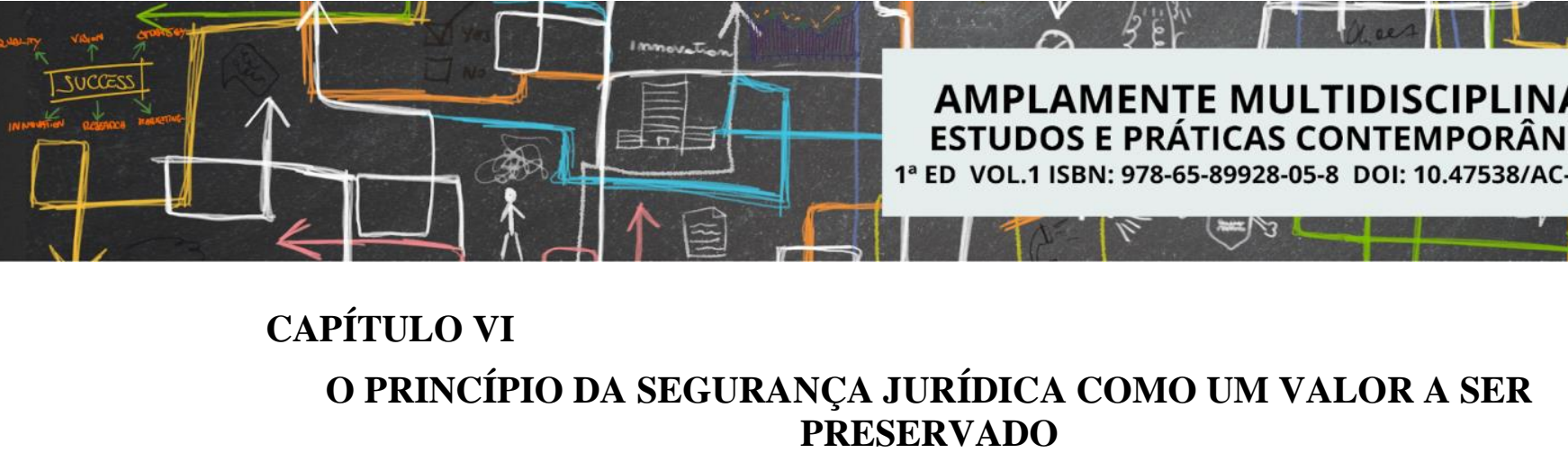

\title{
Leda Mourão da Silva ${ }^{11}$; Ana Flávia Monteiro Diógenes ${ }^{12}$. DOI-CAPÍTULO: 10.47538/AC-2021.07-06
}

\section{RESUMO:}

O presente texto elenca a aplicabilidade da segurança jurídica no campo do Direito Público Brasileiro como um valor social para a ordem jurídica social. A Constituição brasileira consagra o princípio da segurança jurídica em mais de uma oportunidade. Já no desenvolvimento se enuncia que o Estado Democrático de Direito, arrimo da República Federativa do Brasil, está destinado a garantir, entre outros direitos fundamentais, a segurança. Nessa lógica sócio-dogmática, a presença do princípio da segurança jurídica no Texto Maior representa uma evolução, não garantista precedente ao ano de 1988 do Estado, concebida no mesmo nível da justiça.

PALAVRAS-CHAVE: Princípio. Segurança. Jurídica. Justiça.

\section{THE PRINCIPLE OF LEGAL SECURITY AS A VALUE TO BE PRESERVED}

\begin{abstract}
:
This text lists the applicability of legal security in the field of Brazilian Public Law as a social value for the social legal order. The Brazilian Constitution enshrines the principle of legal certainty in more than one opportunity. In development, it is stated that the Democratic Rule of Law, the mainstay of the Federative Republic of Brazil, is destined to guarantee, among other fundamental rights, security. In this socio-dogmatic logic, the presence of the principle of legal certainty in the Larger Text represents a non-guarantee evolution preceding the year 1988 of the State, conceived on the same level as justice.
\end{abstract}

KEYWORDS: Principle. Safety. Legal. Justice.

\section{INTRODUÇÃO}

A importância do estudo reside no fato de se analisar as medidas para efetivação de justiça, tutelando não apenas o interesse da administração, mas, sobretudo, a garantia de direitos fundamentais.

No que tange à metodologia, este texto começou a ser formatado por meio de pesquisa bibliográfica onde foram analisados os textos dos maiores administrativistas do

\footnotetext{
${ }^{11}$ Lattes: http://lattes.cnpq.br/8042384163242265. E-mail: leda.mourao@gmail.com

${ }^{12}$ Lattes: http://lattes.cnpq.br/1222789295507636. E-mail: anaflavia.monteirodiogenes@ gmail.com
} 


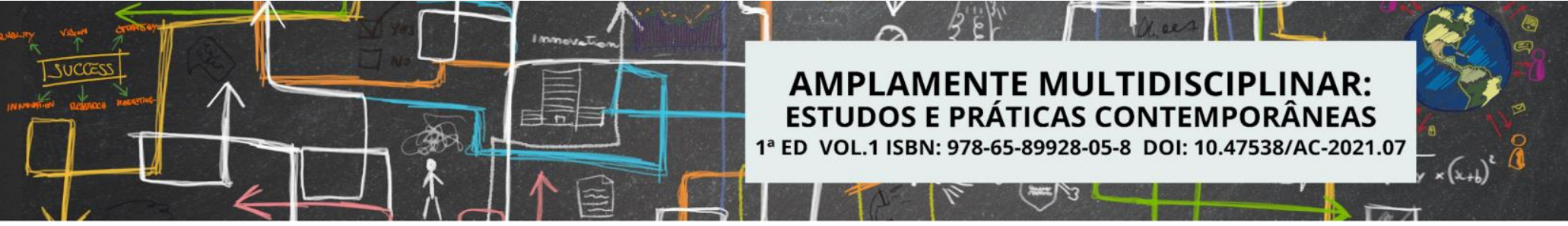

Administração, não pode ser aplicada de forma absoluta e a qualquer tempo.

\section{A QUESTÃO DA DECADÊNCIA NA LEI N. 9784/99}

A Lei Federal n. 9.784/99, que dispõe sobre o procedimento administrativo no plano da Administração Federal Direta e Indireta, dispõe em seu artigo 54:

Art.54. O direito da Administração de anular os atos administrativos de que decorram efeitos favoráveis para os destinatários decai em cinco anos, contados da data em que foram praticados, salvo comprovada máfé.

$\S 1^{\circ}$ No caso de efeitos patrimoniais contínuos, o prazo de decadência contar-se-á da percepção do primeiro pagamento.

$\S 2$ - Considera-se exercício do direito de anular qualquer medida de autoridade administrativa que importe impugnação à validade do ato. (g.m).

Apesar de o mencionado artigo estar contido numa legislação no âmbito do processo administrativo da Administração Pública Federal, a regra prevista acima se estende a toda atividade administrativa de cunho decisório da Administração Federal, não se restringindo apenas aos atos do processo administrativo. Por esse fato, ainda cabe mencionar que, a partir da previsão do artigo 54 da citada Lei, a decadência passou a não mais ser apenas prevista no âmbito da autotutela administrativa.

Esta reflexão ainda é ponderada pelo Professor Almiro do Couto e Silva ${ }^{26}$, em brilhante estudo deste fenômeno. Esse célebre autor, com maestria, afirma que não haveria sentido caso a extinção do direito de anular seus atos ficasse restrita à Administração Pública.

Mister ressaltar que o dispositivo acima é de decadência e não de prescrição, posto que o que se extingue pelo transcurso de prazo, salvo comprovada má-fé, é o direito da Administração de pleitear a anulação do ato nas esferas judiciais e com base no poder de autotutela.

Dessa forma, extrai-se do artigo 54, como já dito acima, que trata a decadência de anular seus atos administrativos, e não da eficácia por eles produzida, permanecendo,

\footnotetext{
${ }^{26}$ SILVA, Almiro do Couto e. O princípio da segurança jurídica (proteção à confiança) no Direito Público Brasileiro e o Direito da Administração Pública de anular seus próprios atos administrativos: o prazo decadencial do art. 54 da Lei do Processo Administrativo Administrativo da União (Lei n. 9784/99).
} 


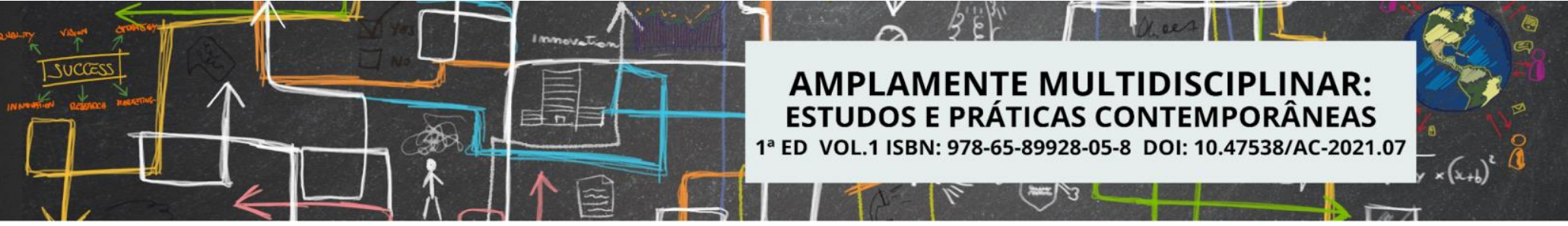

fé, o que não pode, data máxima vênia, é o uso indiscriminado de tal instituto.

\section{REFERÊNCIAS}

ÁVILA, Humberto. Teoria dos Princípios: da definição à aplicação dos princípios jurídicos. $7^{a}$ Ed. São Paulo: Malheiros, 2007.

BIGOLIN, Giovani. Segurança Jurídica: a estabilização do ato administrativo. Porto Alegre: Livraria dos Advogados, 2007.

BRASIL. Constituição da República Federativa do Brasil. Brasília: Senado Federal, publicada no Diário Oficial da União em 05/10/1988. In: <http://www.planalto.gov.br/ccivil_03/constituicao/constitui\%C3\%A7ao.htm> Acesso em: $\langle 26$ de julho de 2021>.

Cf. Jorge Reinaldo Vanossi, El Estado de derecho em el constitucionalismo social, p. 30, citado por José Afonso da Silva in Curso de Direito Constitucional Positivo. São Paulo: Malheiros, 2003.

DI PIETRO, Maria Sylvia Zanella. Direito Administrativo. 20. ed. São Paulo: Atlas, 2007.

HOBBES, Thomas. 1651: Leviatã. Trad. Alex Martins. São Paulo: Martin Claret. Mandado de Segurança n. 24268/MG, rel. Ministra Ellen Gracie, Tribunal Pleno, julgado em 04/02/2004, DJ de 17-09-2004. In: < http://stf.jusbrasil.com/jurisprudencia/ 769533/mandado-de-seguranca-ms-24268-mg>. Acesso em: <27 julho.2021〉.

MANDADO DE SEGURANÇA n. 25116/DF, rel. Ministro Ayres Britto, Tribunal Pleno, julgado em 8/9/2010, Dje de 10/2/2011. In: <http://www.jusbrasil.com.br/ jurisprudencia/busca?q=MS+25116\%2FDF\&s $=$ jurisprudência $>$. Acesso em: $\langle 27$ de julho de 2021>.

MAZZA, Alexandre. Manual de Direito Administrativo. $3^{\text {a }}$ Ed. São Paulo: Saraiva, 2013.

MELlo, Celso Antônio Bandeira de. Curso de direito administrativo. São Paulo: Malheiros, 2010.

NASSAR, Elody. Prescrição na administração pública. $2^{\mathrm{a}}$ Ed. São Paulo: Saraiva, 2009. 


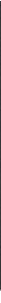

\title{
CAPÍTULO VII
}

\section{O SOFRIMENTO NO TELETRABALHO}

\author{
Renato dos Santos Lisboa ${ }^{36}$; Angélica Costa Mesquita ${ }^{37}$; \\ Fabricio Molica de Mendonça ${ }^{38}$. \\ DOI-CAPÍTULO: 10.47538/AC-2021.07-07
}

\section{RESUMO:}

Na sociedade atual, devido a velocidade das inovações das ferramentas da telemática e o seu uso indispensável no campo do teletrabalho, a execução desse modo de trabalho à distância apresenta percalços no que se refere ao gozo do período de descanso, onde o funcionário encontra dificuldades de se desconectar de suas atividades para o lazer e o convívio familiar. Transpondo ao teletrabalho, pode-se pensar em o trabalhador não executar a tarefa de maneira satisfatória, deve-se ver no ângulo desse trabalhador o porquê isso está ocorrendo, deve-se ver nas diversas áreas do trabalho o que ele deveria estar fazendo e quais as condições ele está tendo e assim conseguir redefinir junto com o trabalhador o que é necessário para que ele consiga realizar a tarefa de uma maneira mais próxima que a organização espera, adequando suas crenças as expectativas da empresa, ou pelo menos diminuindo diferenças que possam existir. Deve ser de interesse da organização coibir o sofrimento, pois quando o assédio ocorre dentro do ambiente de trabalho, pode contaminá-lo, pois não envolve somente agressor e vítima, mas toda a equipe que presencia e vivência esse tipo de ocorrência, e que ao final, acaba atingida de forma negativa, fazendo com a empresa tenha que trabalhar de forma árdua na recuperação de suas equipes, que acabaram atingidas por situações extremas de desgaste e conflito. O teletrabalho é visto, pela a maioria das pessoas, como algo que favorece a vida dos trabalhadores, sendo almejado e sonhado por muitas pessoas, pois oportuniza estar mais tempo com a família entre outras vantagens, entretanto, é de grande importância que o trabalhador tenha cuidado com a gestão do trabalho no tempo, na

\footnotetext{
${ }^{36}$ Neuropsicanalista, MasterCoach, Socorrista em Saúde Mental, Mentor, Advice Humanizado, Advogado e Jornalista. Como advogado foi responsável pela maior negociação Trabalhista do Brasil. É mestrando em Teoria da decisão pelo Cefet - MG e mestre em Psicanálise pelo Instituto Oraculo. Pós-Graduado em Neurociência, Direito Material e Processual do Trabalho, em Administração de Conflitos e Gestão Empresarial, em inteligências múltiplas, mindfulness e em Big Data (Ciência dos Dados). Possui formação Profissional e Especialização em Wellness \& Health Coaching, Global Coach Certification $\odot$, Leader Coach, Trainer de Analistas Comportamentais e Diretor Nacional de Expansão da AbrapCoaching onde também exerce a diretoria Regional em Minas Gerais, é presidente do Instituto Lisboa, Membro do Instituto Brasileiro de Neurociências e membro do Instituto Brasileiro de Psicanálise Clínica. Autor e coautor de diversos livros na área de desenvolvimento humano, onde atua como articulista científico e palestrante. Email: renatodslisboa@gmail.com

${ }^{37}$ Mestranda em Teoria da decisão pelo Cefet - MG é bacharel em direito pela Universidade Federal de Ouro Preto. Pós-graduada em direito público pela Universidade Cândido Mendes. Pós-graduada em gestão pública municipal pela Universidade Federal de Juiz de Fora. Servidora do Tribunal Regional do Trabalho da $2^{\text {a }}$ Região.E-mail: angelicamesquita@gmail.com

38 Graduado em Administração (1992) e Mestre (1996) pela Universidade Federal de Viçosa e Doutorado em Engenharia de Produção pela Universidade Federal do Rio de Janeiro (2008). Atualmente é professor na Universidade Federal de São João del-Rei e participa de três programas de mestrado: Mestrado acadêmico em Administração no CEFET-MG; Mestrado acadêmico no Programa de Pós-graduação em Desenvolvimento, Planejamento e Território (PGDPLAT) e Mestrado profissional em Propriedade Intelectual, Transferência de Tecnologia para Inovação. Em termos de pesquisa, suas atividades sãoo ligadas às temáticas que envolvem Processos decisórios, Gestão Organizacional, Desenvolvimento local, Aglomerados produtivos, Mapeamento e análise de processos, Gestão de pequenas e microempresas e Custos.E-mail: fabriciomolica@yahoo.com.br
} 


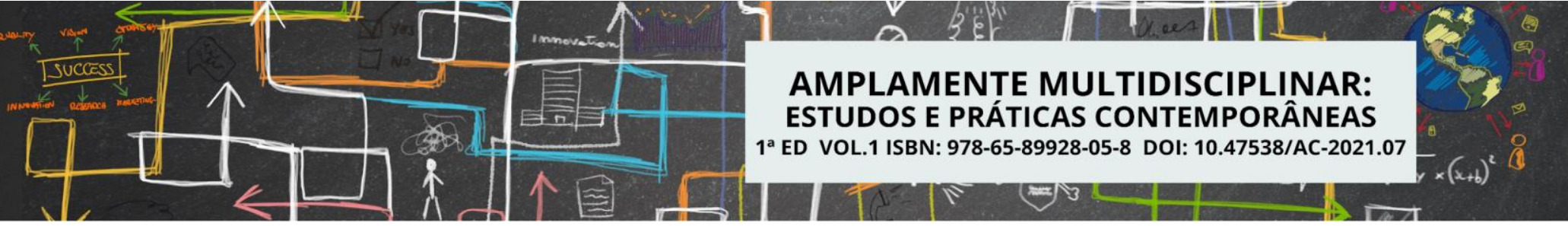

de substituir as vagas retiradas das ruas. Emilson sugere que os comerciantes invistam no aperfeiçoamento dos seus estabelecimentos para receber clientes; o poder público destine ruas pouco movimentadas para abrigar carros; e a população comece a atentar para a importância das garagens

O titular do Projeto VIA LIVRE, Secretário da Semob na época, o Sr. Kelps Lima, concorda com as afirmações do especialista ouvido pela nossa equipe de reportagem. Segundo o secretário, "o disciplinamento dos estacionamentos é só o início de um novo conceito de trânsito na capital".

Segundo o autor do Projeto Via Livre o mesmo foi criado para remediar a situação do trânsito da capital e, além de devolver às ruas para o tráfego de carros. "O Via Livre trabalha também com recapeamento, arborização, iluminação, segurança (com as câmeras de vigilância) e a sincronização semafórica nas vias", informou. O trabalho realizado nas avenidas conta com um serviço conjunto entre a Semob e outras pastas da gestão municipal, como a Secretaria Municipal de Serviços Urbanos (Semsur), que será responsável pelo aspecto visual das vias contempladas.

Questionado sobre os efeitos negativos que o projeto pode causar aos estabelecimentos comerciais, Kelps disse que os empresários já aderiram à ideia. Para o secretário, a mudança despertará os empresários para a importância dos estacionamentos em seus comércios. "Investir em estacionamento agrada ao cliente. Esse é um aspecto importante da nova cultura de trânsito. Os empresários vão se adaptar ao novo modo de se pensar a mobilidade em Natal. Eles devem investir em estrutura para aproveitar o maior número de circulação de pessoas em frente aos seus estabelecimentos".

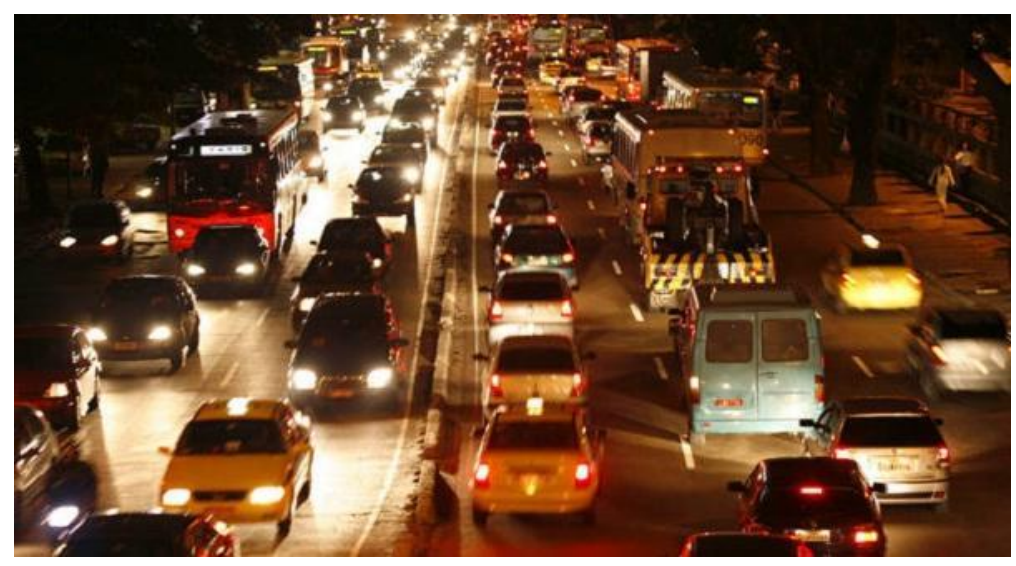




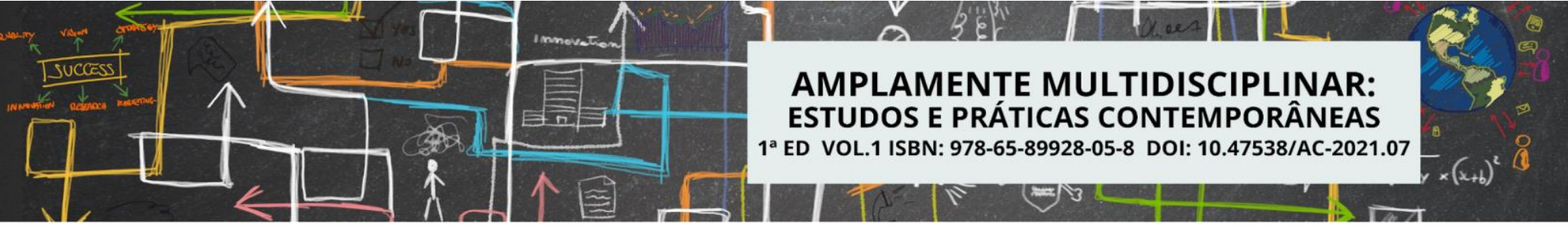

ASSOCIAÇÃO NACIONAL DE TRANSPOTES PÚBLICOS. Projeto transporte humano. São Paulo: Editora ANTP, 1999.

BRASIL. Lei federal 10.257/2001. Dispõe sobre o Estatuto da Cidade. Brasília: DOU, 2001

COSTA, Ademir Araújo da. A verticalização e as transformações do espaço urbano de Natal-RN. Rio de Janeiro.UFRJ, PPPG, 2000(Tese).

DEPARTAMENTO ESTADUAL DE TRÂNSITO DO RIO GRANDE DO NORTE. Dados estatísticos do trânsito em 2006. Natal: RN ECONÔMICO, 2007. 


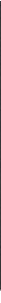

CAPÍTULO X

POPULAÇÃO E MEIO AMBIENTE: CONFLITOS SOCIOAMBIENTAIS

Rosane Machado de Oliveira ${ }^{50}$
DOI-CAPÍTULO: $10.47538 /$ AC-2021.07-10

\title{
RESUMO:
}

O presente capítulo busca discutir e obter respostas em relação à questão do crescimento populacional e os conflitos sociais com o meio ambiente, como por exemplo, as mudanças climáticas e o desmatamento em massa que acabou afetando ainda mais a atmosfera havendo alteração no clima e afetando todo o planeta terra. O objetivo geral da pesquisa foi analisar a elevação do clima no que diz ao efeito estufa e a perfuração da camada de ozônio devido ao processo da industrialização e ao desmatamento de diversas áreas verdes, incluindo a Amazônia. O objetivo específico foi compreender o crescimento populacional e os conflitos provocados no meio ambiente pelas ações dos seres humanos no espaço em que vivem. O procedimento metodológico utilizado neste trabalho é de natureza qualitativa com ênfase na pesquisa bibliográfica. Com base no tema apresentado constatou-se que as mudanças climáticas tiveram e ainda têm interferência do homem no meio em que vive, por meio da industrialização e do desmatamento que acabou atingindo o meio ambiente de modo catastrófico e elevando a temperatura das águas, do solo e da terra.

PALAVRAS-CHAVE: Amazônia. Crescimento Populacional. Desmatamento. Indústria. Mudanças Climáticas.

\section{POPULATION AND THE ENVIRONMENT: SOCIAL AND ENVIRONMENTAL CONFLICTS}

\begin{abstract}
:
This chapter seeks to discuss and obtain answers in relation to the issue of population growth and social conflicts with the environment, such as climate change and massive deforestation that ended up affecting the atmosphere even more with climate change and affecting the whole the planet earth. The general objective of the research was to analyze the increase in the climate in terms of the greenhouse effect and the perforation of the ozone layer due to the industrialization process and the deforestation of several green areas, including the Amazon. The specific objective was to understand population growth and the conflicts caused in the environment by the actions of human beings in the space in which they live. The methodological procedure used in this work is qualitative in nature with an emphasis on bibliographical research. Based on the theme presented, it was found
\end{abstract}

50Graduada em Licenciatura Plena em Pedagogia pela Faculdade Internacional de Curitiba -PR (FACINTER). Graduada em Licenciatura Plena em História pela Faculdade Internacional de Curitiba -PR (FACINTER). Graduada em Licenciatura Plena em Sociologia pela Faculdade Internacional de Curitiba -PR (FACINTER). Especialização em Educação Especial e Inclusiva (FACINTER). Especialização em Docência do Ensino Superior pela Faculdade de Educação São Luís de São Paulo - SP. Especialização em Gestão Escolar: orientação e supervisão pela Faculdade de Educação São Luís de São Paulo - SP. Especialização em Ensino Lúdico pela Faculdade de Educação São Luís de São Paulo - SP. Professora na rede estadual de ensino. instituição de ensino vinculada: a Faculdade Internacional de Curitiba -PR (FACINTER). Lattes: http://lattes.cnpq.br/5978747851727744. E-mail: strbvc@hotmail.com 


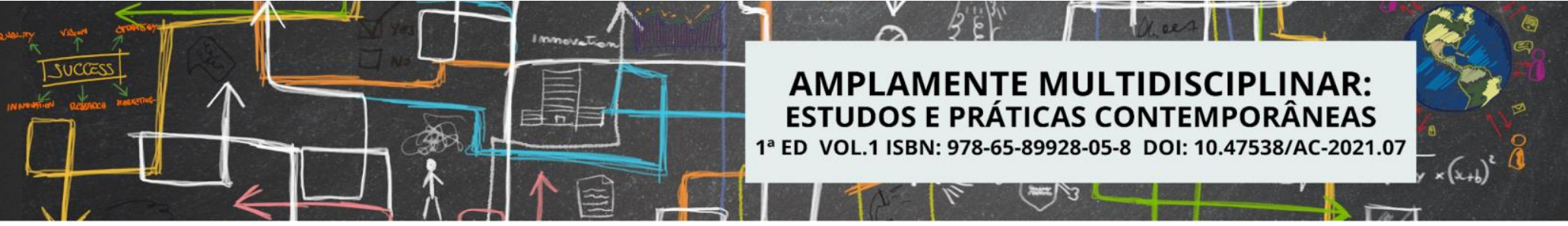

causar câncer de pele e cataratas.

O grande impacto na natureza e no meio ambiente ainda se dá por meio de atividades desenvolvidas pelo homem que infelizmente age de forma irracional diante da exploração dos recursos naturais e dos problemas ambientais.

\section{A QUESTÃO DO DESMATAMENTO}

É preciso que tenhamos a devida compreensão que o desmatamento não ocorre porque as pessoas são más ou porque detestam árvores (folhas, galhos, raízes, troncos), mas porque desmatar faz parte da vida, da sobrevivência humana, ou seja, da própria economia.

É importante que haja consciência sobre a ação de desmatar, repondo de forma justa os recursos que são extraídos da natureza através do plantio das áreas desmatadas e demais áreas, preservando e equilibrando constantemente o meio ambiente.

É imprescindível a necessidade do ser humano adotar hábitos saudáveis em relação à biodiversidade e a preservação da vida na terra. Verifica-se que, por vezes, o que falta é uma determinada consciência nos indivíduos sobre suas ações no meio em que vivem.

O desmatamento e a exploração das terras brasileiras tiveram grande influência dos portugueses com a chegada de Pedro Álvares Cabral no Brasil, desde a primeira missa, com uma cruz construída toda de madeira. Quando analisado o passado histórico, é possível analisar em documentos como livros, cartas e imagens, que os portugueses se interessaram pelas terras brasileiras por haver possibilidades mercantilistas muito atrativas e lucrativas para Portugal, como a extração da madeira chamada Pau-Brasil.

Em pleno século XXI, faz-se necessário que o ser humano saiba conciliar economia e meio ambiente, isto é, agir com respeito e responsabilidades no que diz ao planeta em que habita, pois os recursos naturais devem ser desfrutados por todos com dignidade, e não explorados e utilizados por uma minoria da população.

É fundamental que os indivíduos tenham conhecimento da relevância de preservar, respeitando a legislação vigente. É essencial replantar de modo coerente para 


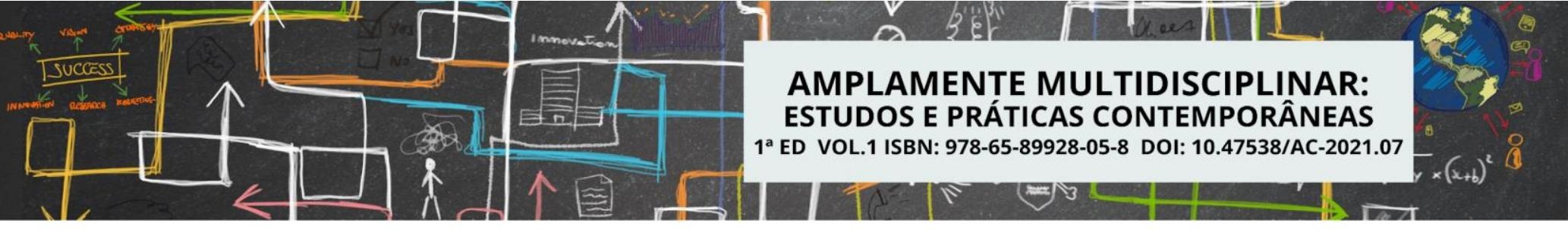

\title{
CAPÍTULO XI
}

\section{VICISSITUDES NO ORDENAMENTO JURÍDICO A PARTIR DE CONSIDERAÇÕES DA DICOTOMIA SEXUALIDADE-RELIGIÃO}

\author{
Edite Batista de Albuquerque ${ }^{51}$; Helmo Robério Ferreira Meneses ${ }^{52}$; \\ Eniglecia Souza de Lima ${ }^{53}$; Ailton Batista de Albuquerque Junior ${ }^{54}$. \\ DOI-CAPÍTULO: 10.47538/AC-2021.07-11
}

\section{RESUMO:}

O presente trabalho aborda as principais evoluções no âmbito jurídico sobre a sexualidade, trazendo a dicotomia entre religião e a identidade de gênero, visto que a Constituição Federal de 1988 garante direitos nas duas perspectivas, por meio da ação declaratória e reconhecedora de direitos nas relações homoafetivas. Dessa forma, objetiva-se identificar fatores que contribuíram com a elaboração de leis infraconstitucionais no ordenamento jurídico brasileiro capazes de diminuir os sofrimentos psicológicos enfrentados no cotidiano como o enfrentamento da LGBTfobia, a qual é responsável pelas agressões físicas, morais e psicológicas em diversos âmbitos da sociedade brasileira. A metodologia aplicada para a concretização deste trabalho foi a pesquisa bibliográfica, inserida no campo do Direito Constitucional, Direito Civil, Direito Processual Civil e decisões julgadas pelo Supremo Tribunal Federal (STF) e Superior Tribunal de Justiça (STJ), incluindo a Lei de Registros Públicos. Além disso, a pesquisa utilizou de abordagem explicativa. Em suma, identificou-se que o Direito é o garantidor de relações, que dirime conflitos, sendo o fator relevante que ocasionou a concretização de direitos às pessoas transexuais, uma vez que suas postulações chegaram ao Judiciário, sendo a jurisdição investida de poder estatal para solucionar conflitos através de sentenças que se concretizam por meio de processos. Percebeu-se também, que as discussões causaram entendimentos jurisprudências e a legiferação de leis infraconstitucionais, sendo que as divergências entre religião e a identidade de gênero sobrevivem em um mesmo espaço jurídico, um não interferindo no direito do outro, como outrora imiscuir. Logo, é possível um Estado Democrático de Direito conviver com dicotomias, desde que uma não interfira no direito de outrem.

PALAVRAS-CHAVE: Gênero. Sexualidade. LGBTQIA+. Direitos Humanos. Discriminação.

\section{VICISSITUDES IN THE LEGAL ORDER BASED ON CONSIDERATIONS OF}

\section{THE SEXUALITY-RELIGION DICHOTOMY}

\section{ABSTRACT:}

51 Graduação em Recursos Humanos (KURIOS-FAK). Especialização em Direito Administrativo e Econômico (INTERVALE). Acadêmica em Direito (UNIFIC). E-mail: editealbuquerque1991@gmail.com. http://lattes.cnpq.br/0749969506040595.

52 Mestre em Sistemas Agroindústrias - UFCG, Graduado em Direito - URCA, Professor - UniFIC: associated institute (Faculdades Integradas do Ceará - UniFIC), advogado. E-mail: helmo_rob@ hotmail.com 53 Acadêmica em Direito (UNIFIC). E-mail: eniglecia@hotmail.com 54 Mestre em Avaliação de Políticas Públicas (UFC). Especialista em Gênero e Diversidade na Escola (UFC) e Gênero, Diversidade e Direitos Humanos (UNILAB). Professor de Educação Básica de Itapipoca/CE: Email: pedagogo.uece@hotmail.com. 


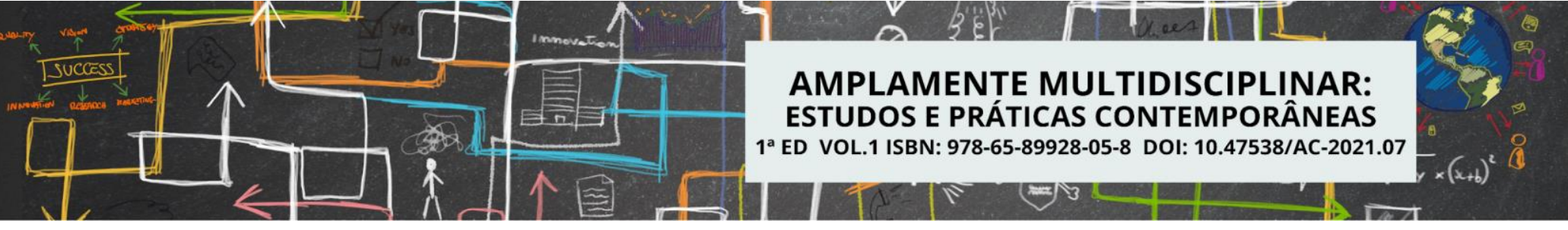

\section{SOBRE OS ORGANIZADORES}

PAIVA, Luciano Luan Gomes: Diretor de Arte na Editora Amplamente Cursos, coordenando toda a produção visual e ações de publicidade nas redes sociais e site da empresa. No campo da Educação, atua como Coach Educacional, Palestrante, Ministrante de Oficinas (presenciais e on-line), Tutor a Distância na Universidade do Estado do Rio Grande do Norte (UERN) e Professor de Música em múltiplos contextos. Como pesquisador, tem feito estudos sobre Aprendizagem mediada por Tecnologias Digitais sob a ótica da Complexidade; Formação Docente no âmbito das Tecnologias Digitais; e Mediação Pedagógica no Ciberespaço. Também é membro do Grupo de Estudos e Pesquisa em Música (GRUMUS-UFRN). Tem formação acadêmica, como Mestre em Música (com ênfase em Educação Musical) pela Universidade Federal do Rio Grande do Norte (UFRN). Especialista em Tecnologias Educacionais e Educação a Distância pelo Instituto Federal de Educação, Ciência e Tecnologia (IFRN). Licenciado em Música pela Universidade Federal do Rio Grande do Norte (UFRN). Orcid: https://orcid.org/0000-0001-6192-6075. Lattes: http://lattes.cnpq.br/0772088747598226. E-mail: luciano.90@hotmail.com.

FREITAS, Dayana Lúcia Rodrigues de: Doutoranda em Ciências da Educação pelo Centro de Educação Continuada e Aperfeiçoamento Profissional (CECAP). Mestra em Ciências da Educação pelo Centro de Educação Continuada e Aperfeiçoamento Profissional (CECAP). Especialista em Mídias na Educação pela Universidade Estadual do Rio Grande do Norte (UERN). Especialista em Tecnologias Educacionais e Educação a Distância pelo Instituto Federal de Educação Ciências e Tecnologia do Rio Grande do Norte (IFRN). Especialista em Metodologia do ensino de Biologia e Química pelo Instituto Pedagógico de Minas Gerais (IPEMIG/MG). Especialista em Educação Ambiental e Geografia do semiárido pelo Instituto Federal de Educação Ciências e Tecnologia do Rio Grande do Norte (IFRN). Especialista em Ensino de Ciências Naturais e Matemática pelo Instituto Federal de educação Ciências e Tecnologia do Rio Grande do Norte (IFRN). Especialista em Língua Portuguesa, Matemática e Cidadania pelo Instituto Federal de Educação Ciências e Tecnologia do Rio Grande do Norte (IFRN). Graduada em Licenciatura Plena em Biologia pelo Instituto Federal de Educação Ciências e Tecnologia do Rio Grande do Norte (IFRN). Graduada em Pedagogia pela UNOPAR. Técnica em Meio Ambiente pelo Serviço Nacional de Aprendizagem Comercial (SENAC/RS). Palestrante. Pesquisadora. Professora e Orientadora de cursos de Pós-Graduação e Graduação em instituições da rede privada em Macau/RN. Professora; Orientadora de TCC e Orientadora de Estágio Curricular Supervisionado da Escola Técnica Fanex Rede de Ensino - Macau/RN. Professora da Educação Básica do município de Guamaré/RN. Orcid: https://orcid.org/0000-00015355-3547. Lattes: http://lattes.cnpq.br/5122671799874415. E-mail: dayannaproducoes@gmail.com. 


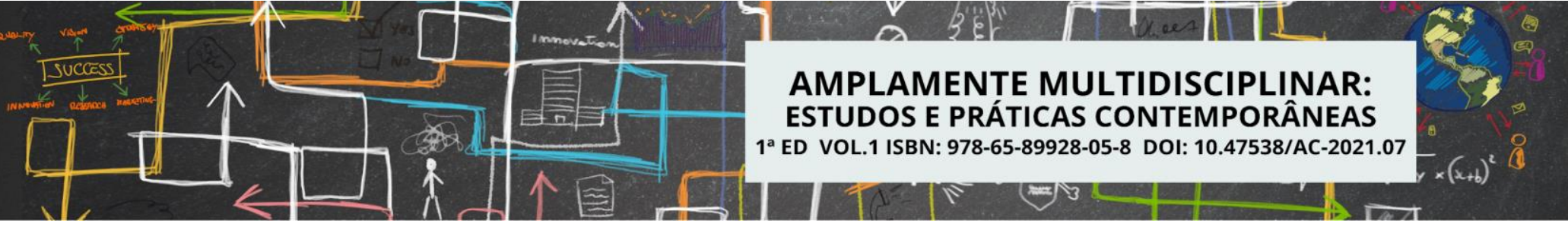

em Neurociência, Direito Material e Processual do Trabalho, em Administração de Conflitos e Gestão Empresarial, em inteligências múltiplas, mindfulness e em Big Data (Ciência dos Dados). Possui formação Profissional e Especialização em Wellness \& Health Coaching, Global Coach Certification $\$, Leader Coach, Trainer de Analistas Comportamentais e Diretor Nacional de Expansão da AbrapCoaching onde também exerce a diretoria Regional em Minas Gerais, é presidente do Instituto Lisboa, Membro do Instituto Brasileiro de Neurociências e membro do Instituto Brasileiro de Psicanálise Clínica. Autor e coautor de diversos livros na área de desenvolvimento humano, onde atua como articulista científico e palestrante. Email: renatodslisboa@gmail.com

LUIZ, Elizandra Aparecida: Mestranda em Educação Ambiental na USP. Lattes: http://lattes.cnpq.br/4891011148682692. E-mail: elizandra-luiz@usp.br

MARTINS, Aline Ramos: Mestre pelo Programa de Pós- Graduação em Rede Nacional para o Ensino das Ciências Ambientais - USP - São Carlos. Professora efetiva do Estado de São Paulo. Lattes: http://lattes.cnpq.br/8604691384555369. E-mail: alinerm@usp.br

MARTINS. Rosa de Lima: Graduada em Pedagogia pela Universidade Estadual Do Vale Do Acaraú. Pós-graduação em Psicopedagogia clínica e institucional pela FAIBRA. Professora do município de Guamaré/RN. E-mail: rosalima87@Gmail.com

MENDES, Fernando Bastos. Graduação em Medicina pela Universidade do Grande Rio (2008). Médico anestesiologista. Tem experiência na área de Medicina, com ênfase em Medicina Peri-operatoria. Lattes: CV: http://lattes.cnpq.br/5736310652434775. E-mail:bmsm.anestesia@gmail.com

MENDONÇA, Fabricio Molica de: Graduado em Administração (1992) e Mestre (1996) pela Universidade Federal de Viçosa e Doutorado em Engenharia de Produção pela Universidade Federal do Rio de Janeiro (2008). Atualmente é professor na Universidade Federal de São João del-Rei e participa de três programas de mestrado: Mestrado acadêmico em Administração no CEFET-MG; Mestrado acadêmico no Programa de Pós-graduação em Desenvolvimento, Planejamento e Território (PGDPLAT) e Mestrado profissional em Propriedade Intelectual, Transferência de Tecnologia para Inovação. Em termos de pesquisa, suas atividades sãoo ligadas às temáticas que envolvem Processos decisórios, Gestão Organizacional, Desenvolvimento local, Aglomerados produtivos, Mapeamento e análise de processos, Gestão de pequenas e microempresas e Custos. E-mail: fabriciomolica@yahoo.com.br

MENESES, Helmo Robério Ferreira: Mestre em Sistemas Agroindústrias UFCG, Graduado em Direito - URCA, Professor - UniFIC: associated institute (Faculdades Integradas do Ceará - UniFIC), advogado. E-mail: helmo_rob@ hotmail.com

MESQUITA, Angélica Costa: Mestranda em Teoria da decisão pelo Cefet - MG é bacharel em direito pela Universidade Federal de Ouro Preto. Pós-graduada em direito público pela Universidade Cândido Mendes. Pós-graduada em gestão pública municipal 


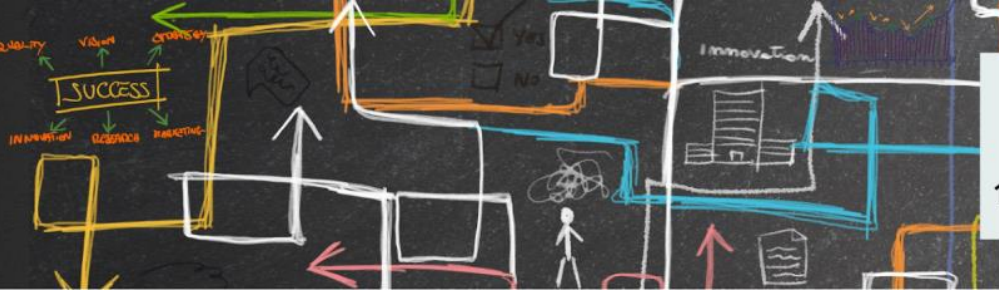

\title{
AMPLAMENTE MULTIDISCIPLINAR:
} ESTUDOS E PRÁTICAS CONTEMPORÂNEAS $1^{2}$ ED VOL.1 ISBN: 978-65-89928-05-8 DOI: 10.47538/AC-2021.07

\section{E-BOOK}

\section{AMIPLAMINTHE \\ MULTIDISCIPLINAR: \\ ESTUDOS E PRÁTICAS \\ CONTHMPORÂNAAS}

$1^{\text {a }}$ EDIÇÃO. VOLUME 01.

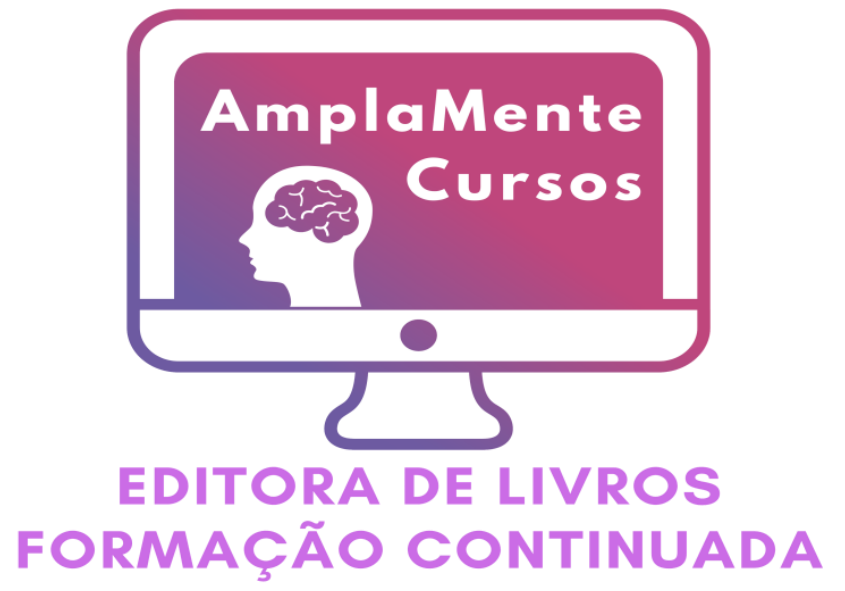

\author{
ORGANIZADORES \\ Luciano Luan Gomes Paiva \\ Dayana Lúcia Rodrigues de Freitas \\ Caroline Rodrigues de Freitas Fernandes
}

DOI: $10.47538 / A C-2021.07$

ISBN: 978-65-89928-05-8

\begin{abstract}
(84) 997072900
(0) @editoraamplamentecursos

f amplamentecursos

Mpublicacoes@editoraamplamente.com.br
\end{abstract}

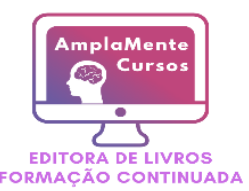

Ano 2021 